\title{
Atomic Structure and Handedness of the Building Block of a Biological Assembly
}

\author{
Antoine Loquet, Birgit Habenstein, Veniamin Chevelkov, Suresh Kumar Vasa, Karin Giller, Stefan Becker, \\ and Adam Lange*
}

Department of NMR-based Structural Biology, Max Planck Institute for Biophysical Chemistry, Am Fassberg 11, 37077 Göttingen, Germany

Supporting Information

ABSTRACT: Noncovalent supramolecular assemblies possess in general several unique subunit-subunit interfaces. The basic building block of such an assembly consists of several subunits and contains all unique interfaces. Atomic-resolution structures of monomeric subunits are typically accessed by crystallography or solution NMR and fitted into electron microscopy density maps. However, the structure of the intact building block in the assembled state remains unknown with this hybrid approach. Here, we present the solid-state NMR atomic structure of the building block of the type III secretion system needle. The building block structure consists of a homotetrameric subunit complex with three unique supramolecular interfaces. Side-chain positions at the interfaces were solved at atomic detail. The high-resolution structure reveals unambiguously the helical handedness of the assembly, determined to be right-handed for the type III secretion system needle.Additionally, the axial rise per subunit could be extracted from the tetramer structure and independently validated by mass-per-length measurements.

$\mathrm{M}$ any biological macromolecular assemblies, such as filaments, fibrils, or capsids, consist of multiple copies of protein subunits in a symmetrical arrangement. The building block of these assemblies is defined as the smallest set of subunits that contains all unique subunit-subunit interfaces, similar to the concept of the asymmetric unit in crystallography. The structure determination of supramolecular assemblies remains a challenging task, mostly due to the noncrystallinity that severely restricts the use of X-ray crystallography. The fitting of crystal subunit structures into density maps obtained from electron-microscopy (EM) offers nowadays ${ }^{1-4}$ a suitable approach to obtain three-dimensional (3D) models of biological assemblies. Nevertheless, despite major improvements in EM methodology, density maps with a resolution sufficient to decipher atomic details about individual subunits in the assembly are still very scarce. ${ }^{5,6}$

Solid-state NMR spectroscopy (ssNMR) provides a powerful complementary method to X-ray crystallography, solution $\mathrm{NMR}$, and EM for the investigation of biological molecular machines in their assembled state. ${ }^{7}$ Atomic information that can be extracted from ssNMR data opens the way to characterize the structure, interactions, and dynamics of biomolecular complexes of growing complexity. ${ }^{8-17}$ We recently reported a complete $3 \mathrm{D}$ atomic model of a biological assembly in its filamentous state, the type III secretion system (T3SS) needle. ${ }^{18,19}$ The T3SS needle is formed by the helical repetition of a single protein subunit (named PrgI for the Salmonella typhimurium T3SS). Structural modeling of this system was complicated due to the presence of three different unique intermolecular interfaces (Figure 1A,B): an axial (between subunits $i$ and $i+11$ ) and two lateral interfaces (between $i$ and $i$ +5 or $i$ and $i+6$, respectively). The smallest building block that needs to be considered in order to reconstruct an atomic structure is therefore a tetramer, consisting of the four subunits (i), (i+5), (i+6), and (i+11) (Figure 1C). In our previous study, ${ }^{18}$ we combined ssNMR data (secondary chemical shifts and distance restraints), a low-resolution EM map, ${ }^{20}$ and information about the axial symmetry (from scanning transmission $\mathrm{EM}^{20}$ ) in an integrative approach using the fold-anddock protocol developed by Baker and co-workers ${ }^{21}$ to fold PrgI monomers in a 3D assembly model of the T3SS needle. Because the procedure made use of state-of-the-art modeling, the question arises whether a classical NMR structure calculation would result in the same atomic model. Herein we report the determination of the atomic resolution structure of the tetrameric building block of the T3SS needle, solely based on ssNMR-derived information. Furthermore, in our previous study we could not unambiguously determine the handedness of the assembly, as both right- and left-handed filaments satisfied the input data, while the Rosetta interface energy was more favorable for right-handed needles.We are now able to address this critical issue, showing that the needle filament adopts a right-handed geometry.

The use of selectively ${ }^{13} \mathrm{C}$-labeled glucose (i.e., $\left[1-{ }^{13} \mathrm{C}\right]$ glc and $\left.\left[2-{ }^{13} \mathrm{C}\right] \mathrm{glc}\right)$ as the carbon source during bacterial T3SS needle subunit overexpression was a key point to establish a high ${ }^{13} \mathrm{C}$ spin dilution", resulting in significant improvements of the ssNMR spectral quality ${ }^{22}$ and to allow for the collection of unambiguous distance restraints. ${ }^{18,23,24}$ Similar selective labeling schemes based on selectively labeled glycerol sources (i.e., $\left[1,3-{ }^{13} \mathrm{C}\right]$ gly and $\left[2-{ }^{13} \mathrm{C}\right]$ gly) were successfully used to determine ssNMR structures of microcrystalline protein$\mathrm{s}^{25,26}$ and amyloid fibrils. ${ }^{27,28}$ So far, a careful comparison of these different selective labeling schemes, especially the resulting effect on the ${ }^{13} \mathrm{C}$ spectral resolution and the labeling

Received: August 22, 2013

Published: December 13, 2013 

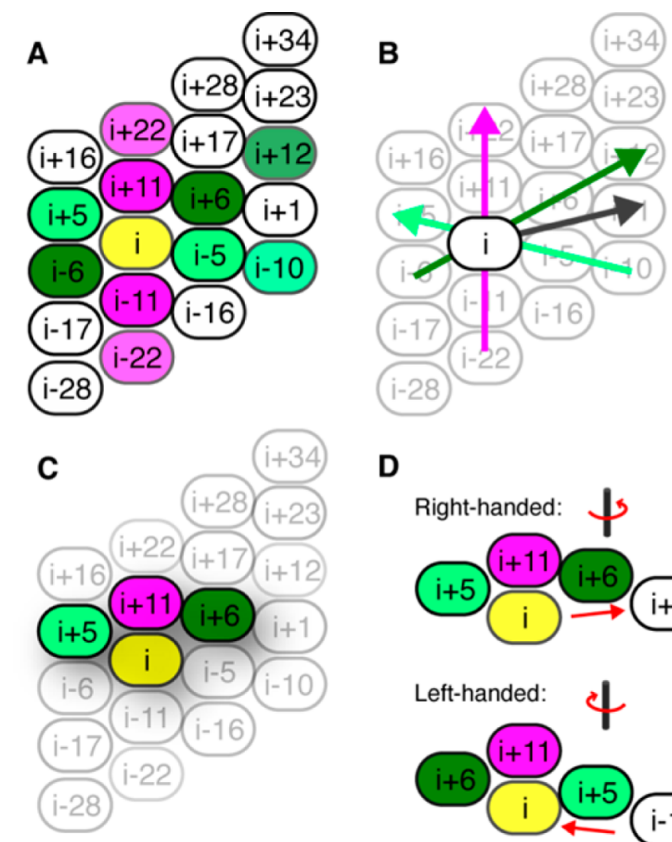

D
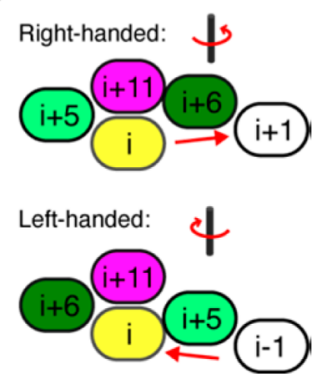

Figure 1. (A) Intermolecular interfaces in the type III secretion system needle (subunit name: PrgI for S. typhimurium). (B) Arrows indicate the directions of the three interfaces of subunit $i$ in the building block: one axial interface (pink) and two lateral interfaces (dark green and light green). The direction of the subunit assembly $(\mathrm{i} \rightarrow \mathrm{i}+1)$ is indicated in black. (C) T3SS needle building block ("asymmetric unit"), containing four subunits. (D) Possible handedness in the T3SS needle indicated by the subunit nomenclature.

efficiency (determining the NMR sensitivity), is missing. We produced $S$. typhimurium T3SS needles with $\left[1-{ }^{13} \mathrm{C}\right] \mathrm{glc}$, $\left[2-{ }^{13} \mathrm{C}\right]$ glc, $\left[1,3-{ }^{13} \mathrm{C}\right] \mathrm{gly}$, and $\left[2-{ }^{13} \mathrm{C}\right]$ gly carbon sources and recorded $1 \mathrm{D}$ cross-polarization spectra to evaluate the spectral resolution and sensitivity in the ${ }^{13} \mathrm{C}$ dimension (Figure SI.1 in Supporting Information $[\mathrm{SI}]) .\left[2-{ }^{13} \mathrm{C}\right]$ glc- and $\left[2-{ }^{13} \mathrm{C}\right]$ glylabeled T3SS needles are comparable in resolution in the aliphatic region, while a small improvement is observed for the $\left[2-{ }^{13} \mathrm{C}\right]$ glc-labeled sample in the carbonyl region (Figure SI.2 in SI). More notable differences are observed when comparing $\left[1-{ }^{13} \mathrm{C}\right]$ glc- and $\left[1,3-{ }^{13} \mathrm{C}\right]$ gly-labeled samples (Figure SI.3 in $\mathrm{SI})$, where the ${ }^{13} \mathrm{C}$ resolution is clearly improved for $\left[1-{ }^{13} \mathrm{C}\right] \mathrm{glc}$. These results can be explained by the different number of labeled carbon sites (i.e., $1 / 6,1 / 6,2 / 3$, and $1 / 3$ respectively for $\left[1-{ }^{13} \mathrm{C}\right] \mathrm{glc}, \quad\left[2-{ }^{13} \mathrm{C}\right] \mathrm{glc},\left[1,3-{ }^{13} \mathrm{C}\right] \mathrm{gly}$, and $\left.\left[2-{ }^{13} \mathrm{C}\right] \mathrm{gly}\right)$ that directly affect the reduction of one-bond dipolar and $J$ couplings, the main sources of homogeneous line-broadening in uniformly labeled T3SS needles. ${ }^{22}$ The better ${ }^{13} \mathrm{C}$-resolution enhancements observed for selectively glucose-labeled samples are counterbalanced by a lower sensitivity (as fewer carbons are labeled), found here to be $\sim 0.85$ (measured as the ratio between $\left[1-{ }^{13} \mathrm{C}\right] \mathrm{glc} /\left[1,3-{ }^{13} \mathrm{C}\right] \mathrm{gly}$ and $\left[2-{ }^{13} \mathrm{C}\right] \mathrm{glc} /\left[2-{ }^{13} \mathrm{C}\right] \mathrm{gly}$ signal intensities in $1 \mathrm{D}$ spectra. A stronger effect is expected in $2 \mathrm{D}$ spectra, as $2 \mathrm{D}$ cross-peaks require the presence of two labeled carbons. This effect favors glycerol-labeled samples, where spectra encoding for long-range distance restraints can be recorded with very high sensitivity.

We next performed $2 \mathrm{D}{ }^{13} \mathrm{C}-{ }^{13} \mathrm{C}$ experiments (Figure SI.4 in SI) on the $\left[1,3-{ }^{13} \mathrm{C}\right]$ gly- and $\left[2-{ }^{13} \mathrm{C}\right]$ gly-labeled T3SS needle samples to collect a large set of distance restraints. The highresolution in the ${ }^{13} \mathrm{C}$ dimension allows for an assignment with a very high precision (see Figure $2 \mathrm{~B}$ for an excerpt). The digital

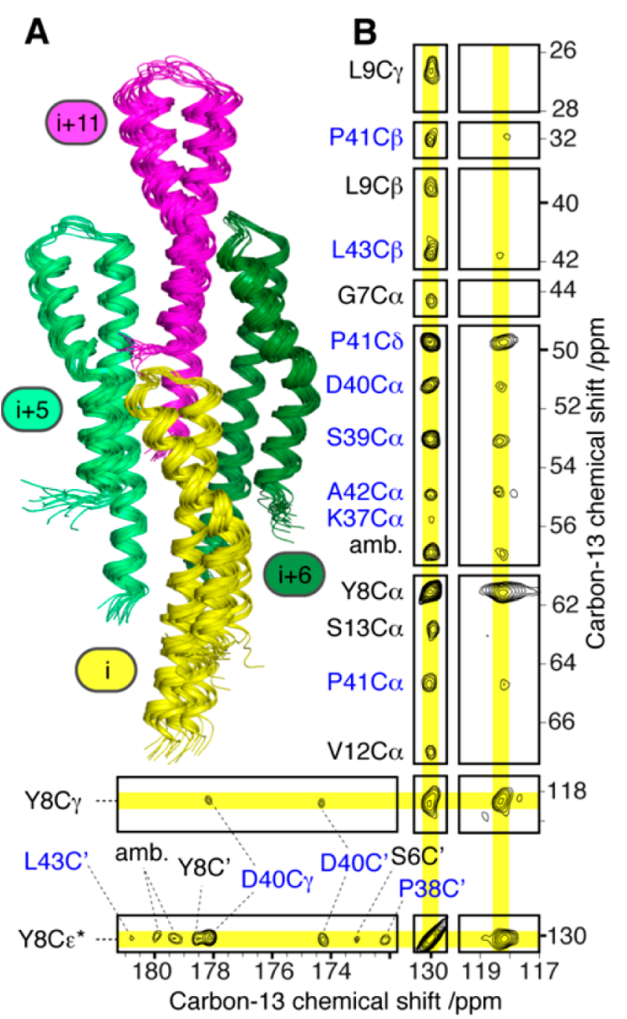

Figure 2. (A) Solid-state NMR structure (15 lowest-energy tetramers) of the tetrameric PrgI building block of the Salmonella typhimurium type III secretion system needle. (B) Assignment of the solid-state NMR distance restraints for tyrosine 8 (atoms $\mathrm{C} \gamma$ and $\mathrm{C} \varepsilon$ ). The spectral excerpt is from a PDSD spectrum (mixing time $800 \mathrm{~ms}$ ) recorded on $\left[2-{ }^{13} \mathrm{C}\right]$ glycerol-labeled PrgI needles (see Figure SI.4 in SI for full spectrum).

resolution was improved compared to that of our previously reported spectra ${ }^{18}$ by the use of longer acquisition times, while the total experimental time was kept approximately as before. The approach can be readily combined with $3 \mathrm{D}$ spectroscopy, ${ }^{24,29}$ and we thus recorded $a{ }^{15} \mathrm{~N}-{ }^{13} \mathrm{C} \alpha-{ }^{13} \mathrm{CX}$ experiment on $\left[2-{ }^{13} \mathrm{C}\right]$ gly-labeled T3SS needles, to provide additional restraints (encoded as ${ }^{13} \mathrm{C} \alpha-{ }^{13} \mathrm{CX}$ contacts) (Figure SI.5 in SI). A total of 831 long-range (residues $|i-j|>4$ ) restraints were collected (Table SI.1 in SI), including 251 intra- and 580 intersubunit restraints. Note, that these numbers include the long-range restraints on glucose-labeled samples reported before in ref 18 (comprising 85 intra- and 162 intersubunit restraints). While intrasubunit and axial intersubunit restraints could be identified in a straightforward manner due to the monomer subunit topology (Figure SI.8A in SI and ref 18), the distinction between the two lateral interfaces (i.e., (i) $-(\mathrm{i}+5)$ and $(\mathrm{i})-(\mathrm{i}+6))$ was realized by iterative structure calculations of PrgI homotrimers (see SI) to continually discard the most violated contributions, in analogy to routines used in $\mathrm{ARIA}^{30}$ or $\mathrm{UNIO},{ }^{31}$ and already applied to ssNMR structure determinations of microcrystalline proteins. ${ }^{32,33}$ Finally, the building block structure was calculated (Figure 2A, backbone r.m.s.d of 1.10 and $2.36 \AA$ for monomeric and tetrameric PrgI, respectively) for a homotetramer that consists of the subunits (i), $(i+5),(i+6)$, and $(i+11)$. This tetramer contains all three of the different unique interfaces (Figure 1C) and can therefore be considered as the "asymmetric unit" of the assembly. The determined long-range restraints are equally distributed along 

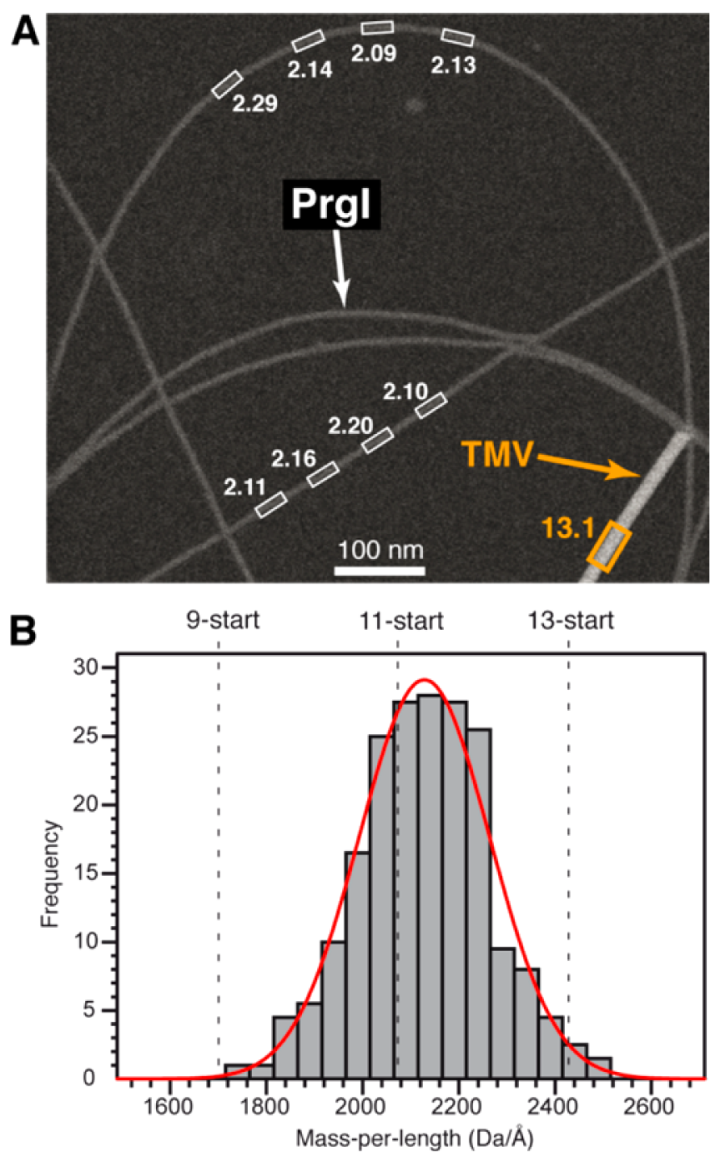

Figure 3. Mass-per-length (MPL) measurements of PrgI needles by STEM. (A) Dark-field STEM image of PrgI needles and TMV reference particles. (B) MPL histogram fitted with a Gaussian function centered at $2.128 \pm 0.027 \mathrm{kDa} / \AA$ and with a full-width at halfmaximum (fwhm) equal to $0.135 \pm 0.02 \mathrm{kDa} / \AA \AA$. The dotted lines represent estimated MPL values for 9-, 11-, and 13-start architectures (i.e., 4.5, 5.5, or 6.5 subunits per turn).

the primary sequence (Figure SI.6 in SI), and each interface is well-defined $(208,212$, and 160 long-range restraints for the axial, lateral $(\mathrm{i})-(\mathrm{i}+5)$, and lateral $(\mathrm{i})-(\mathrm{i}+6)$ interfaces, respectively; Table SI.1 in SI). Notably, the high-resolution structure of the tetrameric needle building block reported in this communication exhibits the same fold and intermolecular arrangement compared to a tetramer extracted from our previous Rosetta model ${ }^{18}$ (Figure SI.7 in SI; backbone r.m.s.d of $1.8 \AA$ for the monomer). The position of the side chains at the intermolecular interfaces (Figure SI.9 in SI) could be determined at unprecedented resolution. Such atomic details are not accessible from the available $7.7 \AA$ cryo-EM map recently obtained on the homologous Shigella flexneri needle. ${ }^{3,35}$ The total number of restraints collected in this study largely exceeds the input data used by us previously to determine the 3D model of the T3SS needle ${ }^{18}(\sim 3$ times more restraints). Considering the size of the PrgI subunit ( 80 residues), the sum of restraints collected by means of glucoseand glycerol-based labeling schemes represents a number of more than 10 nonredundant, meaningful long-range restraints per residue, which is in the range of input data used in standard solution NMR protein structure determination. In our previous study of the T3SS needle, ${ }^{18}$ the handedness of the needle (Figure 1D) was not determined unambiguously. The highresolution structure presented here allows for the extraction of the helical handedness, which was observed to be right-handed. We determined an average axial rise per subunit of $4.16 \pm 2.1$ A. To corroborate this result, scanning transmission EM (STEM) measurements on the ssNMR PrgI T3SS needle sample (Figure 3A) were performed, leading to a mass-perlength of $2.128 \pm 0.027 \mathrm{kDa} / \AA ̊$. This confirms an 11-start helical arrangement (Figure 3B). The value leads to an axial rise per subunit of $9.0511 / 2.128=4.25 \AA$, which is remarkably close to the axial rise extracted from the ssNMR tetramer structure.

The presented results demonstrate the power of ssNMR to determine high-resolution structures of complex biological building blocks, as well as to determine the helical handedness of filamentous assemblies. Ongoing methodological developments in our laboratory combine ssNMR building block structures with EM-based structural data (mass-per-length, density map) to propose robust hybrid approaches to tackle atomic structures of larger assemblies.

${ }^{1} \mathrm{H},{ }^{13} \mathrm{C}$, and ${ }^{15} \mathrm{~N}$ chemical shifts are deposited under the BMRB entry 18276. Coordinates have been deposited under the PDB entry $2 \mathrm{MEX}$.

\section{ASSOCIATED CONTENT}

\section{S Supporting Information}

Experimental details on sample preparation, ssNMR spectroscopy and structure calculations. This material is available free of charge via the Internet at http://pubs.acs.org.

\section{AUTHOR INFORMATION}

\section{Corresponding Author}

adla@nmr.mpibpc.mpg.de

\section{Notes}

The authors declare no competing financial interest.

\section{ACKNOWLEDGMENTS}

This work was supported by the Max Planck Society, the Deutsche Forschungsgemeinschaft (Emmy Noether Fellowship to A.Lange), the Fondation Bettencourt-Schueller (to A.Loquet), and EMBO (postdoctoral fellowships to A.Loquet and B.H.).

\section{REFERENCES}

(1) Fujii, T.; Iwane, A. H.; Yanagida, T.; Namba, K. Nature 2010, 467,724 .

(2) Hryc, C. F.; Chen, D. H.; Chiu, W. Curr. Opin. Virol. 2011, 1, 110.

(3) Milne, J. L.; Borgnia, M. J.; Bartesaghi, A.; Tran, E. E.; Earl, L. A.; Schauder, D. M.; Lengyel, J.; Pierson, J.; Patwardhan, A.; Subramaniam, S. FEBS J. 2013, 280, 28.

(4) Karaca, E.; Bonvin, A. M. Methods 2013, 59, 372.

(5) Ward, A. B.; Sali, A.; Wilson, I. A. Science 2013, 339, 913.

(6) Henderson, R.; Sali, A.; Baker, M. L.; Carragher, B.; Devkota, B.; Downing, K. H.; Egelman, E. H.; Feng, Z.; Frank, J.; Grigorieff, N.; Jiang, W.; Ludtke, S. J.; Medalia, O.; Penczek, P. A.; Rosenthal, P. B.; Rossmann, M. G.; Schmid, M. F.; Schroder, G. F.; Steven, A. C.; Stokes, D. L.; Westbrook, J. D.; Wriggers, W.; Yang, H.; Young, J.; Berman, H. M.; Chiu, W.; Kleywegt, G. J.; Lawson, C. L. Structure 2012, 20, 205.

(7) Loquet, A.; Habenstein, B.; Lange, A. Acc. Chem. Res. 2013, 46, 2070.

(8) Lewandowski, J. R. Acc. Chem. Res. 2013, 46, 2018.

(9) Krushelnitsky, A.; Reichert, D.; Saalwachter, K. Acc. Chem. Res. 2013, 46, 2028.

(10) Ullrich, S. J.; Glaubitz, C. Acc. Chem. Res. 2013, 46, 2164. 
(11) Murray, D. T.; Das, N.; Cross, T. A. Acc. Chem. Res. 2013, 46, 2172

(12) Yan, S.; Suiter, C. L.; Hou, G.; Zhang, H.; Polenova, T. Acc.

Chem. Res. 2013, 46, 2047.

(13) Hong, M.; Schmidt-Rohr, K. Acc. Chem. Res. 2013, 46, 2154.

(14) Tang, M.; Comellas, G.; Rienstra, C. M. Acc. Chem. Res. 2013, 46, 2080.

(15) Sengupta, I.; Nadaud, P. S.; Jaroniec, C. P. Acc. Chem. Res. 2013, 46, 2117.

(16) Knight, M. J.; Felli, I. C.; Pierattelli, R.; Emsley, L.; Pintacuda, G. Acc. Chem. Res. 2013, 46, 2108.

(17) Parthasarathy, S.; Nishiyama, Y.; Ishii, Y. Acc. Chem. Res. 2013, 46, 2127.

(18) Loquet, A.; Sgourakis, N. G.; Gupta, R.; Giller, K.; Riedel, D.; Goosmann, C.; Griesinger, C.; Kolbe, M.; Baker, D.; Becker, S.; Lange, A. Nature 2012, 486, 276.

(19) Loquet, A.; Habenstein, B.; Demers, J. P.; Becker, S.; Lange, A. Med. Sci. (Paris) 2012, 28, 926.

(20) Galkin, V. E.; Schmied, W. H.; Schraidt, O.; Marlovits, T. C.; Egelman, E. H. J. Mol. Biol. 2010, 396, 1392.

(21) Das, R.; Andre, I.; Shen, Y.; Wu, Y.; Lemak, A.; Bansal, S.; Arrowsmith, C. H.; Szyperski, T.; Baker, D. Proc. Natl. Acad. Sci. U.S.A. 2009, 106, 18978.

(22) Loquet, A.; Lv, G.; Giller, K.; Becker, S.; Lange, A. J. Am. Chem. Soc. 2011, 133, 4727.

(23) Loquet, A.; Giller, K.; Becker, S.; Lange, A. J. Am. Chem. Soc. 2010, 132, 15164 .

(24) Habenstein, B.; Loquet, A.; Giller, K.; Becker, S.; Lange, A. J. Biomol. NMR 2013, 55, 1.

(25) Castellani, F.; van Rossum, B.; Diehl, A.; Schubert, M.; Rehbein, K.; Oschkinat, H. Nature 2002, 420, 98.

(26) Franks, W. T.; Wylie, B. J.; Schmidt, H. L.; Nieuwkoop, A. J.; Mayrhofer, R. M.; Shah, G. J.; Graesser, D. T.; Rienstra, C. M. Proc. Natl. Acad. Sci. U.S.A. 2008, 105, 4621.

(27) Wasmer, C.; Lange, A.; Van Melckebeke, H.; Siemer, A. B.; Riek, R.; Meier, B. H. Science 2008, 319, 1523.

(28) Van Melckebeke, H.; Wasmer, C.; Lange, A.; Ab, E.; Loquet, A.; Bockmann, A.; Meier, B. H. J. Am. Chem. Soc. 2010, 132, 13765.

(29) Castellani, F.; van Rossum, B. J.; Diehl, A.; Rehbein, K.; Oschkinat, H. Biochemistry 2003, 42, 11476.

(30) Bardiaux, B.; Malliavin, T.; Nilges, M. Methods Mol. Biol. 2012, $831,453$.

(31) Guerry, P.; Herrmann, T. Methods Mol. Biol. 2012, 831, 429.

(32) Loquet, A.; Bardiaux, B.; Gardiennet, C.; Blanchet, C.; Baldus, M.; Nilges, M.; Malliavin, T.; Bockmann, A. J. Am. Chem. Soc. 2008, $130,3579$.

(33) Manolikas, T.; Herrmann, T.; Meier, B. H. J. Am. Chem. Soc. 2008, 130, 3959.

(34) Fujii, T.; Cheung, M.; Blanco, A.; Kato, T.; Blocker, A. J.; Namba, K. Proc. Natl. Acad. Sci. U.S.A. 2012, 109, 4461.

(35) Demers, J. P.; Sgourakis, N. G.; Gupta, R.; Loquet, A.; Giller, K.; Riedel, D.; Laube, B.; Kolbe, M.; Baker, D.; Becker, S.; Lange, A. PLoS Pathog. 2013, 9, e1003245. 